\title{
Paradigmas em disputa? Debate entre Butler, Benhabib e Fraser
}

\author{
Michele Teixeira Bonote ${ }^{1}$
}

\begin{abstract}
Resumo: O presente artigo revisita um debate na teoria feminista dos anos 1990 entre as teóricas Judith Butler, Seyla Benhabib e Nancy Fraser presente na coletânea Debates Feministas. O objetivo central é compreender a posição política de cada autora em relação às possibilidades - ou não - de um sujeito para o feminismo, que apontariam os caminhos para se pensar a emancipação - como Benhabib indica - ou a subversão - como Butler indica. Iniciamos o artigo com a exposição da teoria da performatividade de gênero de Butler e com o pensamento de Benhabib sobre o self situado; posteriormente apresentamos a disputa política entre as autoras; por final, a partir da leitura de Fraser, trazemos uma tentativa de reconciliação entre os paradigmas que cada autora trabalha.
\end{abstract}

Palavras-chave: Performatividade - Pós-estruturalismo - Teoria crítica - Emancipação Feminismo

\section{Disputing Paradigms? Debate between Butler, Benhabib and Fraser}

\begin{abstract}
This paper revisits a debate in the feminist theory of the 90s between the theorists Judith Butler, Seyla Benhabib and Nancy Fraser present in the collection Feminist Contentions. The central objective is to understand the political position of each author in relation to the possibilities - or not - of a subject for feminism, which would point the way to think about emancipation - as Benhabib indicates - or subversion - as Butler indicates. The article starts with the exposition of Butler's theory of gender performativity and with Benhabib's thought about the situated self; later we present the political dispute between the authors; finally, from Fraser's reading, we bring an attempt to reconcile the paradigms that each author works with.
\end{abstract}

Keywords: Performativity - Post-structuralism - Critical theory - Emancipation - Feminism

\footnotetext{
${ }_{1}^{1}$ Mestranda em Filosofia na Universidade Federal do ABC, orientada pela Prof ${ }^{a}$. Dr ${ }^{a}$. Nathalie de Almeida Bressiani. Bolsista FAPESP. Email: michelebonote@hotmail.com.
} 


\section{Introdução}

Partindo de um recorte da discussão entre Seyla Benhabib e Judith Butler, narrado em Debates Feministas: um intercâmbio filosófico (1995), este artigo tangerá questões sobre as (im)possibilidades de um sujeito para se pensar a agência feminista. Objetivamos reconstruir o debate, atentando-nos à crítica que cada autora faz da concepção de sujeito do projeto Iluminista e, consequentemente, à capacidade de agência e transformação resultante da posição política que cada uma defende.

O texto inicia-se com a exposição da teoria da performatividade de gênero de Judith Butler, que será o ponto de partida da crítica de Benhabib; em seguida, introduz-se o pensamento de Benhabib sobre o self situado; para, então, colocar as autoras em discussão em torno da questão sobre "feminismo e pós-modernismo", mostrando suas críticas e respostas; por final, pretende-se reconciliar as posições aparentemente opostas a partir da leitura de Nancy Fraser, apontando para uma conclusão que una esforços estratégicos para a crítica feminista.

Apesar das divergências, as autoras partem de uma crítica em comum: a crítica ao sujeito transcendental/racional do projeto moderno e Iluminista. A filosofia feminista temnos chamado a atenção para a hegemonia dessa concepção de sujeito do conhecimento que se pretende universal, mas que por muitos séculos expressou a dominação de um pensamento particular. Mesmo que a bandeira da "liberdade, igualdade e fraternidade" tenha sido levantada pelo projeto Iluminista, o mundo ainda estava sendo compreendido a partir da figura do homem, branco, proprietário, cristão, ocidental, colocando-o como o único sujeito do conhecimento, da política e do poder.

O Iluminismo, portanto, que apostava na razão como algo que nos permitiria ir além das particularidades para fundamentar conhecimentos práticos e teóricos universais, defendia, contudo, uma concepção de sujeito universal da razão que não abarcava todos os seres humanos, mas somente uma pequena parcela. Em contraposição ao sujeito racional, atribuiu-se a irracionalidade a todos aqueles que não se encaixavam nesta categoria, o que permitiu a justificação da dominação destes. Tanto a filosofia quanto a história estão marcadas por exemplos dessa exclusão e dominação.

$\mathrm{Na}$ filosofia vemos Kant atribuindo às mulheres uma racionalidade anômala, ao tomá-las como incapazes de dar leis morais a si mesmas ${ }^{2}$ e Hegel declarando explicitamente a ausência de racionalidade e história nos povos africanos ${ }^{3}$. Paralelamente, durante a Revolução Francesa - símbolo da modernidade - vemos Olympe de Gouges redigir um modelo da Declaração dos Direitos do Homem e do Cidadão que contemplasse as mulheres, questionando, portanto, o viés excludente da Revolução.

Benhabib e Butler partem de críticas a este adversário comum. No entanto, os caminhos pelos quais cada uma conduz suas análises resultam em consequências políticas muito diferentes. Enquanto Benhabib defende a reforma dos ideais do Iluminismo, para que se adéquem às demandas dos sujeitos que foram excluídos, Butler aponta para sua desconstrução, apontando o caráter opressor e excludente de promessas universalistas.

\footnotetext{
${ }^{2}$ KANT, Antropologia de um ponto de vista pragmático, p. 205.
}

${ }^{3}$ HEGEL, Filosofia da História, pp. 83-86. 
Fraser, por outro lado, mostra que os argumentos de ambas não são incompatíveis, defendendo uma teoria crítica feminista capaz de unir paradigmas.

Acreditamos que dos anos 1990 até os dias atuais, "o sujeito, categoria moderna que passa pelo século XX sendo descentrado, abalado, reinscrito, reescrito, clivado", como Lobato e Rodrigues sugerem, não perdeu sua centralidade, "cuja razão, desejo e lugar ainda constituem o eixo do debate político contemporâneo"4. As discussões trazidas por este diálogo foram - e continuam sendo - aprofundadas e/ou modificadas nos trabalhos que se seguiram das autoras. Dessa forma, propomos reconstruir a disputa, para mostrar como a questão ainda é pertinente para a teoria feminista e nos oferece um terreno fértil de investigações filosóficas.

\section{Butler e a performatividade de gênero}

Em Problemas de Gênero: feminismo e subversão da identidade (1990), Butler formula uma crítica radical às identidades sociais e à estratégia da política da identidade. Para tanto, ela realiza uma genealogia feminista ao retomar os discursos de poder que estruturaram a identidade "mulheres" como pré-requisito da política feminista. A autora nos mostra a necessidade de questionar o "sujeito" como fundamento para a ação política, contestando as reificações e exclusões provocadas pelo gênero e identidade assumidos pelo movimento feminista até então.

Butler faz isso ao criticar o sistema binário de sexo/gênero que a teoria feminista teria se sedimentado. Quem primeiro sistematiza essa concepção é Gayle Rubin em Tráficos de Mulheres (1975), quando aponta que toda sociedade conta com um sistema sexo/gênero, definido como "um conjunto de arranjos através dos quais uma sociedade transforma a sexualidade biológica em produto da atividade humana" ${ }^{5}$, mostrando que a opressão das mulheres é produto de relações sociais que instituem a desigualdade entre os gêneros.

Foi a partir da divisão sexo/gênero que feministas se embasaram para avançar na construção de teorias sobre a opressão que fossem contra o argumento de que as mulheres eram inferiores e subordinadas aos homens de forma necessária e natural. Nessa equação, o sexo enquadra-se no domínio da natureza, enquanto o gênero no domínio da cultura. No entanto, Butler não aceita a ideia de sexo como uma percepção "natural" e questiona: não seria o sexo, também, uma noção cultural e historicamente construída? Aceitar a ideia de sexo como algo "dado" na natureza significaria fechar os olhos para os conflitos discursivos e políticos que historicamente fizeram culminar o conceito de $\operatorname{sexo}^{6}$. Assim, não é somente a categoria de gênero que é construída, mas também a de sexo; e a relação que as categorias de sexo e gênero têm uma com a outra só pode indicar que ambas nunca foram distintas, apontando para o gênero como o meio discursivo/cultural que produz a ideia de "um sexo natural" que apareceria antes da cultura, como Butler coloca, "uma superfície politicamente neutra sobre a qual age a cultura"'.

Assim, tanto sexo como gênero são produtos de uma ordem cultural. Então, se o gênero independe do sexo, por que não pensar em um espaço aberto para o gênero

\footnotetext{
${ }^{4}$ LOBATO, A; RODRIGUES, C. “Os feminismos e seus sujeitos”, p. 44.

${ }^{5}$ RUBIN, Tráfico de Mulheres, p. 2.

${ }^{6}$ Ideia que aparece em FOUCAULT, M. História da Sexualidade 1: a vontade de saber.

${ }^{7}$ BUTLER, Problemas de Gênero, p. 27.
} 
interpretar o sexo de múltiplas formas e não apenas duas - como homem e mulher? Se o gênero é uma categoria construída e não é dependente da categoria do sexo, então a construção do gênero "homem" não precisa se aplicar exclusivamente a corpos de sexo masculino, por exemplo.

É a partir deste raciocínio que Butler quer mostrar como o sujeito do feminismo é discursivamente constituído por um sistema político que supostamente deveria levá-lo à emancipação, mas que reforça suas posições nessa cadeia unívoca de sexo/gênero/desejo. Ou seja, há em operação, nesse contexto, uma estrutura de poder que naturaliza o sistema binário de gênero ao ocultar seu caráter culturalmente constituído. Disso resulta a imposição da ideia de que a categoria de "mulheres" só seria coerente na medida em que só há dois gêneros (homem/mulher), dois sexos (macho/fêmea) e um único desejo, o heterossexual. A noção de "identidade" em nosso contexto, portanto, só pode ser sustentada por conceitos determinantes de sexo, gênero e desejo, isto é, pela matriz heterossexual, a estrutura hegemônica de poder pela qual o sujeito é constituído a partir de uma heterossexualidade compulsória.

Assim, de acordo com Butler, insistir na categoria universal das "mulheres" seria contrário aos objetivos do feminismo, visto que essa prática também serve para regular e reificar inconscientemente as relações de gênero, em que o termo "mulheres" só aparece como estável e coerente dentro de um sistema binário que exclui possibilidades de sexo, gênero e desejo que estejam fora de parâmetros heterossexuais. É por esse motivo, também, que indivíduos cujo gênero é "incoerente" ou "descontínuo", ou seja, que fogem da regra binária, não são reconhecidos como pessoas.

Quem melhor representa essa "descontinuidade" de gênero, em Problemas de Gênero, são as drag queens, que em suas performances jogam com a oposição da anatomia de quem performa (sexo masculino) e o gênero que está sendo performado (feminilidade), confundindo a correspondência entre sexo, gênero e desejo ao invés de confirmá-la. Butler vê essas "identidades de gênero" como oportunidades críticas de expor os limites do campo de inteligibilidade da matriz heterossexual, disseminando matrizes rivais e subversivas de gênero.

Nesse sentido, Butler compreende o gênero como performativamente constituído. Ela entende que as expressões de gênero são provenientes do discurso hegemônico da matriz de poder heterossexual, e não de "algo substantivo", como uma essência ou emanação do sexo. Afirmar que a identidade de gênero é uma noção performativamente constituída implica dizer que ela não é causa inerente de nada anterior - natural, biológico, corporal - a sua própria "performance", ou melhor, a sua própria ação. Como Salih aponta, "gênero não é algo que somos, é algo que fazemos [...] um verbo em vez de um substantivo, um 'fazer' em vez de um 'ser"'s.

Consequentemente, na medida em que identidades ininteligíveis realizam um deslocamento performativo frente ao sistema binário, ou seja, quando expõem possibilidades de gênero que não decorrem do sexo, ou de desejos sexuais que não decorrem nem do sexo e nem do gênero, a hegemonia da matriz de poder heterossexual é enfraquecida e o sujeito, portanto, colocado em questão.

${ }^{8}$ SALIH, Judith Butler e a teoria Queer, p. 89. 


\section{Benhabib e o self situado}

Ao contrário de Butler, Benhabib é defensora dos ideais do Iluminismo. No entanto, ela também é crítica a esses princípios. Em Situating the Self: gender, community and postmodernism in contemporary ethics (1992), a autora recupera as críticas feministas, comunitaristas e pósmodernas aos ideais do Iluminismo e explicita, por meio delas, as exclusões geradas e/ou justificadas por esses ideais. Longe de levarem Benhabib a abandonar o projeto moderno, estas críticas são reconstruídas pela autora no interior de sua proposta de um "universalismo interativo", por meio do qual ela procura superar os limites do Iluminismo sem abrir mão de suas conquistas.

De maneira geral, Benhabib identifica três críticas que devem ser levadas a sério para a formulação de seu universalismo interativo: 1) o ceticismo quanto a uma "razão universal legisladora", capaz de organizar um ponto de vista moral externo e imparcial; 2) a crítica ao ideal abstrato de um sujeito racional autônomo que mascara o privilégio de um ego masculino e ocidental imposto como "universal"; 3) a crítica à inaptidão do ideal de uma "razão legisladora universal" para se pensar os conflitos morais e políticos que aparecem na multiplicidade dos contextos e das situações de vida nas sociedades contemporâneas. Nos atentaremos à segunda crítica, que se direciona ao sujeito racional.

Em Uma Teoria da Justiça (1971), John Rawls defende que os princípios da justiça são aqueles que decorreriam de um processo de deliberação no qual as partes que deliberam desconhecem as posições que ocupam na sociedade (isto é, se são brancos ou negros, homens ou mulheres, ricos ou pobres etc.). De acordo com ele, seria apenas ao se afastarem de seus interesses específicos, por meio de um artifício de pensamento (a posição original), que as pessoas seriam capazes de formular princípios de justiça ou leis morais universalizáveis que poderiam ser ditos válidos para todos. A universalidade requereria, assim, o afastamento frente às particularidades. Benhabib nos atenta para o fato de que esse ideal atuou, em diversos momentos, para justificar diferentes formas de dominação e exclusão - como exposto na introdução do artigo.

De acordo com a autora, como os atores são sempre social e historicamente situados e participam de práticas políticas e sociais concretas, eles não são capazes de transcender plenamente suas particularidades e desenvolver teorias ou conceitos de justiça objetivos e universais, pelo menos não no sentido indicado acima. É impossível, portanto, que eles adotem um ponto de vista puramente racional que abstraia de toda a experiência. Motivo pelo qual, para ela, todas as tomadas de decisão e posição são concretamente situadas.

Benhabib, portanto, se esquiva da tradição de teorias morais universalistas, que desde Hobbes a Rawls privilegiam a investigação moral da esfera da justiça, constituída por sujeitos de direito abstratos. Uma tradição que, segundo a autora, privilegia aquilo que ela chama de "outro generalizado" e ignora as circunstâncias contingentes, históricas e afetivas da esfera da boa vida, constituída por sujeitos individuais únicos: o "outro concreto". Assim, Benhabib defende uma ética que acabe com esse antagonismo e trate ambos os pontos de vista como complementares, pois, da mesma forma que os sujeitos morais devem se autodeterminar de acordo com normas justas e universais, eles também devem assumir o ponto de vista do outro concreto.

Apesar de levar em conta as críticas feitas por feministas, pós-modernos e comunitaristas para formular sua compreensão, Benhabib ainda levanta algumas questões e 
dúvidas sobre as análises destes. No ensaio "Feminismo e pós-modernismo: uma aliança complicada", a autora expõe a conexão entre feminismo e pós-modernismo e os problemas decorrentes dessa aliança. Para explicitar a conexão entre as correntes, ela utiliza a caracterização apresentada por Jane Flax em Thinking Fragments: Psychoanalysis, Feminism and Postmodernism in the Contemporary West (1990).

Para Flax, o pós-modernismo se caracteriza, em geral, pela defesa de três teses: a morte do Homem, da História e da Metafísica. Segundo ela, com a tese da morte do Homem, "os pós-modernistas querem destruir todas as concepções essencialistas do ser humano ou da natureza", negando a possibilidade de qualquer tipo de transcendência, pois os seres humanos não passariam de sujeitos sociais, históricos e linguísticos. Com a morte da História, por sua vez, se nega a existência do "ser" histórico e a ideia teleológica do progresso moral, pois estas dependem da ficção do Homem, ideia que "privilegia e pressupõe o valor de unidade, homogeneidade, totalidade, finalização e identidade" ${ }^{10}$. Com a morte da Metafísica, por fim, os pós-modernos apontam para a ilusão de sistemas filosóficos absolutos quererem se colocar como representantes da verdade, ou seja, o desejo de "controlar o mundo ao encerrá-lo dentro de um sistema ilusório mas absoluto que acreditam representar ou corresponder a um Ser unitário além da história, da particularidade e da mudança" "11.

Benhabib articula versões feministas destas três teses. A versão feminista da morte do Homem - que nos interessa - é interpretada nos termos de uma Desmistificação do Sujeito Masculino da Rąão. Segundo Benhabib, a filosofia ocidental teria excluído as diferenças de gênero de seus parâmetros para pensar a experiência e a subjetividade do sujeito. $\mathrm{O}$ discurso do sujeito idêntico, colocado pela razão ocidental, teria impedido e deslegitimado a presença de qualquer outro que fosse diferente de suas próprias categorias. Dessa maneira, Benhabib indica que "desde Platão até Descartes a Kant e Hegel a filosofia ocidental tematiza a história de um sujeito masculino da razão"12. Ao colocar a razão como aquilo que nos torna iguais, ela nos cega para a presença da alteridade, tornando necessária a desmistificação da concepção de sujeito neutro e universal da razão.

A filósofa pontua que a aproximação do feminismo com o pós-modernismo se apresenta em teses de gradações fortes e fracas. Para ela, o feminismo só poderia manter uma aproximação fraca com as teses pós-modernas, ou seja, uma posição que "não questionaria o desejo e a necessidade teórica de articular uma visão de subjetividade mais adequada, menos equivocada e menos mistificada", tendo em vista que conceitos tradicionais filosóficos como "autorreflexão, capacidade de atuar por princípios, responsabilidade racional por seus atos e [...] alguma forma de autonomia e racionalidade"13 devem ser preservados e reformulados levando em consideração o sujeito situado.

Por outro lado, a versão forte da tese da morte do Homem destruiria esses conceitos tradicionais, que para Benhabib dão base ao feminismo. Quem melhor captura essa tese é Flax em uma passagem que diz: para o pós-modernismo "o sujeito é meramente uma outra posição na linguagem" ${ }^{14}$, que retira do sujeito a capacidade de iniciador de suas próprias

\footnotetext{
${ }^{9}$ FLAX, Thinking Fragments, p. 32 apud BENHABIB et al., "Feminismo e pós-modernismo", p. 36.

${ }^{10}$ FLAX, Thinking Fragments, p. 33 apud BENHABIB et al., "Feminismo e pós-modernismo", p. 37.

${ }^{11}$ FLAX, Thinking Fragments, p. 34 apud BENHABIB et al., "Feminismo e pós-modernismo", p. 37.

12 BENHABIB et al., "Feminismo e pós-modernismo", p. 39.

13 BENHABIB et al., "Feminismo e pós-modernismo", p. 40.

${ }^{14}$ FLAX, Thinking Fragments, p.32 apud BENHABIB, "Feminismo e pós-modernismo", p. 40.
} 
significações. Assim, por mais que o sujeito situado e de gênero seja determinado de forma heteronômica, isto é, sujeito às narrativas e leis de seu contexto/comunidade, para Benhabib, ele ainda busca a autonomia, isto é, a liberdade de agir a partir de leis que ele mesmo se dá. Por isso ela pergunta: "como o próprio projeto de emancipação feminina seria remotamente possível sem um tal princípio regulador de agência, autonomia e individualidade?"15.

O ponto de vista político de Benhabib, portanto, aponta para um ceticismo em relação à incorporação pós-moderna pelo feminismo que desbanque conceitos filosóficos essenciais para a emancipação. É neste momento que Benhabib expõe Butler como uma das autoras feministas que teria levado as teses pós-modernas ao extremo. Benhabib, portanto, faz uma crítica à teoria da performatividade de gênero.

\section{A disputa}

Mas, afinal, o que significa o conceito de agência e qual sua importância para o debate entre as autoras? $\mathrm{Na}$ teoria política, este conceito está ligado à ideia de ação. Um agente é um ser com capacidade de agir. No feminismo, o modo dominante de pensar a agência é "(quasi-)kantiano", como descreve Llyod: "isto é, onde os atores são considerados independentes do mundo político-social ao seu redor e onde a agência é interpretada como a capacidade tanto de conceber projetos específicos quanto de implementá-los de acordo com sua vontade própria" ${ }^{16}$. Contudo, seria errôneo afirmar que todos os feminismos adotam uma forma de crítica que depende de uma concepção forte de sujeito e de uma agência completamente autônoma. Análises como as de Butler e Benhabib nos mostram como os seres humanos estão profundamente encravados e situados na vida social, em que vemos suas ações limitadas por inúmeros fatores de sua posição cultural, classe social, sexo, gênero, raça, religião, entre outras. Dessa forma, afirma-se que a ação humana é condicionada, mas não completamente determinada por esses fatores - posição de Butler. Porém, algumas feministas acreditam que, ainda assim, alguma parte do sujeito consegue escapar desse condicionamento contextual, fonte da qual a agência surgiria a partir de algo "pré-discursivo" - posição de Benhabib.

Para Benhabib, é essencial que o feminismo não perca de vista um horizonte emancipatório, em que a "autonomia" do sujeito é essencial para pensar sua liberdade de transformar o mundo. Butler, por sua vez, questiona a necessidade de uma posição "prédiscursiva" dos sujeitos para se pensar em ação política. Vejamos, primeiramente, como Benhabib direciona suas críticas.

Para a autora, a teoria da performatividade de Butler, fortemente influenciada por teóricos "pós-modernos", caminha em direção à dissolução do sujeito na cadeia de significações da qual, na realidade, ele deveria ser o iniciador, levando à negação do sujeito, a morte do Homem. Benhabib aponta que essa posição leva ao desmantelamento do sujeito, visto que não seríamos "mais do que a soma total das expressões de gênero que performamos" 17 . Isso a leva perguntar: "existe alguma chance de interromper a performance

\footnotetext{
${ }^{15}$ BENHABIB et al., "Feminismo e pós-modernismo", p. 41.

${ }^{16}$ LLOYD, Judith Butler: from norms to politics, p. 57.

${ }^{17}$ BENHABIB et al., "Feminismo e pós-modernismo", p. 43.
} 
por um momento, de fechar as cortinas e só permitir que se abram de novo quando pudermos opinar na produção da própria peça?’"18.

Além disso, afirma Benhabib, a versão nietzschiana do "mito do dado" teria levado Butler a afirmar que "não há identidade de gênero por trás das expressões de gênero" ${ }^{19}$, uma visão que toma o indivíduo como mascarado e mais ainda, nos leva a acreditar que não há indivíduo algum por trás da máscara. Ora, mas se não há um sujeito, pergunta Benhabib, de onde surgiria o impulso para a transformação social? Para a autora, não importa o quanto se é constituído pela linguagem, o sujeito ainda preserva certa autonomia e habilidade para rearranjar significações da linguagem.

Para concluir, Benhabib indica de maneira geral que teorias "pós-modernas" ou "pós-estruturalistas", como as de Butler, nos abrem os olhos para os perigos de estruturas totalizantes de grandes teorias ou narrativas de legitimação. Para ela, este esforço se torna necessário diante do medo de que a crítica social seja soberana e coercitiva ao buscar um único conjunto de critérios que deteriam um estatuto de validade universal. Entretanto, ela ainda identifica dois problemas com esse tipo de crítica.

O primeiro problema identifica-se pelo sacrifício que o pós-modernismo faz de qualquer modo de normatização. De acordo com Benhabib, a constituição de critérios avaliativos é necessária para caracterizar as práticas sociais, para ela, a crítica social precisa de filosofia para elucidar princípios e ordenar prioridades normativas justamente porque nossas narrativas culturais "são tão conflituosas e irreconciliáveis" ${ }^{20}$ que tal ordenação é inevitável.

O segundo problema "é assumir que as normas constitutivas de determinada cultura, sociedade e tradição serão suficientes para permitir que a crítica seja exercida em nome de um futuro desejado" "21. A autora indica que nos casos em que uma sociedade está dominada por forças reificantes tão brutais que paralisam ou impedem o diálogo e a conversação, o crítico social se torna um exilado social, "de Thoreau à Escola de Frankfurt, de Albert Camus aos dissidentes da Europa do Leste [...] tanto a Antiguidade quanto a Idade Média tiveram filósofos exilados" ${ }^{\text {”2 }}$. Para Benhabib, então, a crítica pressupõe um distanciamento necessário dos consensos de seu meio.

Em resposta, no artigo "Fundações contingentes: feminismo e a questão do "pósmodernismo"', Butler reflete sobre a caracterização redutora e homogeneizante que se faz do pós-modernismo. Como ela explicita, é com o intelectual Jean-François Lyotard que vemos o acolhimento do termo "pós-moderno", em A Condição Pós-Moderna (1979). Entretanto, há autores como Derrida, expoente do pós-estruturalismo, e outros em conflito com a obra de Lyotard, assim como defensores da psicanálise lacaniana se posicionando contra o pós-estruturalismo e assim por diante. Há, portanto, diversos autores com teorias complexas e muitas vezes divergentes que são injustamente tachados como "pós-modernos". Isso faz com que Butler pergunte se todas essas teorias têm a mesma estrutura e, se não têm, por que o esforço para colocá-las todas sobre uma rubrica só? Seria isso sintoma de "uma

\footnotetext{
18 BENHABIB et al., "Feminismo e pós-modernismo", p. 43.

${ }^{19}$ BUTLER, Problemas de Gênero, p. 25 apud BENHABIB, "Feminismo e pós-modernismo", p. 42.

${ }^{20}$ BENHABIB et al., "Feminismo e pós-modernismo", pp. 53-54.

${ }^{21}$ BENHABIB et al., "Feminismo e pós-modernismo", p. 54.

22 BENHABIB et al., "Feminismo e pós-modernismo", p. 54.
} 
simples recusa de dar especificidade a essas teorias, uma desculpa para não ler, ou não ler cuidadosamente?"23, provoca.

Não certa quanto ao termo "pós-moderno", Butler se posiciona adequadamente como pós-estruturalista, indicando que esta é uma análise que visualiza o próprio aparato conceitual que negocia seus termos como impregnado de poder. Butler afirma que essa análise "não é o advento de um relativismo niilista incapaz de fornecer normas"; ao contrário, é uma posição que se configura como "precondição de uma crítica política engajada" ${ }^{24}$. Significativamente, a tentativa de assegurar um sujeito que se encontre em uma posição anterior às negociações políticas de poder, isto é, um eu "pré-discursivo", constitui um ato de poder que "sublima, mascara e estende seus próprios jogos de poder recorrendo a tropos de universalidade normativa" 25 .

Apesar de colocar em questão a categoria do sujeito, Butler não pensa em desmantelá-la completamente. Sua principal tarefa é fragilizar sua estrutura firme, mostrando-a como um lugar de disputa política constante. É assim que a autora defende que uma teoria social comprometida com um projeto político radical deve buscar de alguma maneira colocar em questão os próprios fundamentos em que é obrigada a se estabelecer. Afirmar que a delimitação do sujeito se constitui por uma série de procedimentos excludentes e seletivos não implica afirmar a morte do sujeito, mas sim interrogar a maneira como entendemos seu surgimento e sua capacidade de ação.

Com isso, sua principal crítica é a de que a agência é geralmente associada com o pressuposto do sujeito antes da lei. Mas, ela pergunta, será que precisamos mesmo pressupor teoricamente um sujeito atribuído de agência antes de articular uma agenda política de resistência? Se não é oferecida essa garantia teórica de um eu "pré-discursivo", então necessariamente se está fadado a abrir mão de uma transformação e prática política relevante? ${ }^{26}$

Butler sugere, portanto, que consideremos a agência não mais a partir de uma existência formal, como uma garantia a priori, atributo de um sujeito também a priori. Contrariamente é preciso compreender que a agência é "sempre e somente uma prerrogativa política" 27 . A capacidade de agir e transformar, então, reside nas possibilidades de mobilização produzida pelas próprias configurações de discurso e poder que já existem. Como o sujeito é constituído, produzido e sujeitado a todo instante, o poder não cessa de configurá-lo num processo contínuo de ressignificação. Para Butler, é nesse movimento dinâmico que surgem possibilidades de retrabalhar a matriz do poder a partir de dentro dela mesma - como as drags fazem ao ressignificar o feminino. Neste sentido, sua crítica ao sujeito não significa seu aniquilamento total; ela comenta: "realizar esse tipo de crítica foucaultiana do sujeito não é excluir o sujeito ou declarar sua morte, mas apenas afirmar que certas versões do sujeito são politicamente insidiosas" 28 e que a teoria feminista deveria estar sempre atenta a esses pressupostos $^{29}$.

\footnotetext{
${ }^{23}$ BUTLER et al., "Fundações contingentes", p. 65.

24 BUTLER et al., "Fundações contingentes", p. 68.

${ }^{25}$ BUTLER et al., "Fundações contingentes", p. 68.

${ }^{26}$ BUTLER et al., "Fundações contingentes", p. 80.

${ }^{27}$ BUTLER et al., "Fundações contingentes", p. 80.

${ }^{28}$ BUTLER et al., "Fundações contingentes", p. 81.

${ }^{29}$ É relevante notar que Butler não contesta a necessidade de falar como e para mulheres no feminismo. Como ela afirma: "esse é, certamente, o modo pelo qual opera a política de representação e, nos Estados Unidos,
} 


\section{Em busca de horizontes comuns}

Interlocutora da discussão, Nancy Fraser, no artigo "Falsas antíteses: uma resposta a Seyla Benhabib e Judith Butler", defende que a maneira pela qual Butler e Benhabib desenvolvem a discussão acaba resultando em uma polarização que não é verdadeira. Fraser aposta que teoria crítica e pós-estruturalismo não são incompatíveis e sustenta que é tarefa do feminismo realizar a reconstrução de ambas as propostas que permita reconciliá-las. Vejamos as críticas que ela aponta para cada autora.

Segundo Fraser, é positiva a abordagem de Benhabib ao identificar teses fracas e fortes que unem feministas a pós-modernos, pois parece que entre esses extremos há uma terceira via, em que a autora desenvolveria sua visão de crítica social situada. No entanto, Benhabib não chega a desenvolver essa alternativa. Como Fraser coloca, "em vez de aprofundar a lógica de seu argumento, ela conclui que a crítica situada não é boa o suficiente e que, assim, não pode haver crítica social sem filosofia" ${ }^{30}$.

Fraser contesta essa afirmação, mostrando que tudo depende do que se quer dizer com os termos "crítica situada" e "filosofia". Para ela, nem toda crítica situada sacrifica a necessidade de reconstrução e elucidação de normas sociais ${ }^{31}$; aliás, essas críticas sustentam práticas de esclarecimento e reconstrução das normas que são necessariamente cultural e historicamente situadas. Assim, tanto a crítica, como sua autoelucidação são situadas e nenhuma delas requer filosofia, "se 'filosofia' significa um discurso que aspira ser o pensamento fundacionalista definitivo" 32 , ou seja, um discurso a-histórico, transcendental, que afirma articular os critérios de validade para todos os outros discursos. Portanto, para Fraser, a crítica situada não destrói a possibilidade de normatizações, mas "apenas exige que elas também sejam vistas como situadas" ${ }^{33}$.

Sobre a segunda objeção de Benhabib, Fraser pontua que não se convence com o argumento de que a "crítica situada não pode ser usada para casos nos quais uma cultura ou sociedade está tão mal que o crítico social é levado ao exílio (literal ou metaforicamente)"34. Quando um crítico social é levado ao exílio, como foram os teóricos da Escola de Frankfurt pelo Terceiro Reich, ele não parte sem bagagem alguma; ao contrário, ele parte "como um crítico culturalmente formado e culturalmente situado" 35 .

Em relação a Butler, Fraser acredita que esta consegue responder às críticas que Benhabib aponta em sua teoria, mas traz novas questões para a autora. Apesar de Butler afirmar que não existe estrutura de subjetividade que não seja desde sempre o resultado de uma matriz de poder, os indivíduos não são pré-determinados e suas capacidades críticas devem ser apreendidas dentro da própria formatação cultural em que se enquadram. A

\footnotetext{
esforços de lobby são virtualmente impossíveis sem recorrer à política identitária" (BUTLER et al., "Fundações contingentes", p. 84). O que ela traz de novo é mostrar como essa necessidade precisa ser reconciliada concomitantemente a abertura e ressignificação permanente da categoria mulher.

${ }^{30}$ FRASER et al., "Falsas Antíteses", p. 101.

31 Identifica sua teoria e de Nicholson como alternativa de um meio termo. Cf. FRASER; NICHOLSON, "Social Criticism without Philosophy".

32 FRASER et al., "Falsas Antíteses", p. 102.

${ }^{33}$ FRASER et al., "Falsas Antíteses", p. 103.

${ }^{34}$ FRASER et al., "Falsas Antíteses", p. 103.

${ }^{35}$ FRASER et al., "Falsas Antíteses", p. 103.
} 
agência, então, apareceria na própria constituição do sujeito, que é um "terreno de ressignificações" constante.

Nesta discussão, o que preocupa a autora são questões sobre como prever, diagnosticar e caracterizar as capacidades críticas de forma mais estratégica. De acordo com ela, o uso que Butler faz do termo "ressignificação" possui uma carga positiva forte - ainda que implícita -, o que a faz comparar "ressignificação" com o termo "crítica" que usa em suas análises. Porém, como diagnostica, "em outro sentido, os dois termos diferem por completo" "36, visto que ressignificar não carregaria nenhuma implicação de validade ou autoridade - essencial para sua compreensão de crítica. Assim sendo, Fraser afirma que as conotações positivas da ressignificação que Butler evoca são no mínimo intrigantes, o que a faz questionar: "por que ressignificação é positiva? Não poderia haver ressignificações ruins (opressoras, reacionárias)?" ${ }^{37}$. Para a autora, Butler opta por uma operação epistemologicamente neutra, que parece dar mais ênfase na mudança por si mesma, "desempoderando", portanto, o julgamento feminista.

Ademais, Fraser coloca que ao seguir a formulação de Foucault, Butler insistiria na constituição dos sujeitos através de um processo excludente, que implica necessariamente a sua sujeição. Como Fraser afirma, "ela [Butler] insiste que os sujeitos são constituídos por meio da exclusão; algumas pessoas são autorizadas a falar com autoridade porque outras são silenciadas" ${ }^{38}$. Mas, Fraser pergunta, será que em todos os casos, quando um torna-se sujeito necessariamente outros são silenciados? E onde tais exclusões existem, elas são todas igualmente ruins? "Podemos construir práticas, instituições e formas de vida nas quais o empoderamento de alguns não acarrete o desempoderamento de outros? Se não, qual a razão da luta feminista?" 39 .

Para concluir, Fraser defende que posições como as de Butler e Benhabib são unilaterais, mas, para a autora, os processos de desconstrução e de reconstrução são dois lados da mesma moeda pós-fordista. Por isso, a crítica social feminista deveria travar um caminho bilateral e flexível, que trabalhe tanto com o paradigma Moderno, quanto com o Pós-Moderno, unindo teoria crítica e pós-estruturalismo em um esforço conjunto de análise e proposição que constituiria um horizonte comum.

\section{Considerações finais}

As contribuições deste debate para a teoria feminista não se esgotam neste volume. Judith Butler, que foi alvo de inúmeras críticas causadas pela recepção de Problemas de Gênero, dedicou-se, ao longo dos anos 1990, ao esclarecimento de sua teoria e posicionamento político com a publicação de Corpos que Importam (1993), A Vida Psíquica do Poder (1997) e Excitable Speech (1997), sem contar com o diálogo que continuou travando com Nancy Fraser em artigos publicados na revista New Left Review ${ }^{40}$.

A proposta de unir teoria crítica e pós-estruturalismo, como defendida por Fraser, talvez ainda seja um desafio para a atualidade. Como a autora coloca, é inevitável que os

\footnotetext{
${ }^{36}$ FRASER et al., "Falsas Antíteses", p. 108.

${ }^{37}$ FRASER et al., "Falsas Antíteses", p. 108.

38 FRASER et al., "Falsas Antíteses", p. 109.

${ }^{39}$ FRASER et al., "Falsas Antíteses", p. 109.

${ }^{40}$ Cf. BUTLER, J; BRETAS, A, "Meramente Cultural".
} 
movimentos feministas façam reivindicações em nome das "mulheres", algo que Benhabib defende e a que nem Butler se atreve a se opor; por outro lado, "mulheres" é uma categoria que sempre deve estar sujeita à desconstrução. Somente assim conseguiremos compreender as complexidades da subjetivação, munidas de ferramentas para o reconhecimento da alteridade, ao mesmo tempo em que poderemos direcionar ações políticas de forma estratégica.

\section{Referências bibliográficas}

BENHABIB, Seyla et al. "Feminismo e pós-modernismo: uma aliança complicada". In: BENHABIB, S.; BUTLER, J.; CORNELL, D.; FRASER, N. Debates feministas: um intercâmbio filosófico. Trad. Fernanda Veríssimo. São Paulo: Unesp, 2018a.

BENHABIB, Seyla. Situating the Self: Gender, community and postmodernism in contemporary ethics. New York: Routledge, 1992.

BENHABIB, Seyla; BUTLER, Judith; CORNELL, Drucila; FRASER, Nancy. Debates feministas: um intercâmbio filosófico. Trad. Fernanda Veríssimo. São Paulo: Unesp, 2018.

BULER, Judith et al. "Fundações contingentes: feminismo e a questão do 'pósmodernismo"'. In: BENHABIB, S.; BUTLER, J.; CORNELL, D.; FRASER, N. Debates feministas: um intercâmbio filosófico. Trad. Fernanda Veríssimo. São Paulo: Unesp, 2018b.

BUTLER, Judith. Excitable Speech: A Politics of the Performative. Routledge, New York \& London, 1997.

. A Vida Psiquica do Poder: Teorias em Sujeição. Belo Horizonte: Autêntica, 2019a.

2019b.

Corpos que Importam: os limites discursivos do "sexo". São Paulo: N-1 Edições,

. Problemas de Gênero: Feminismo e subversão da identidade. Rio de Janeiro: Civilização Brasileira, 2016.

BUTLER, Judith; BRETAS, Aléxia. "Meramente cultural". Ideias, Campinas, SP, v. 7, n. 2, pp. 227-248, 2017.

FLAX, Jane. Thinking Fragments: Psychoanalysis, Feminism, and Postmodernism in the Contemporary West. Berkeley: University of California Press, 1990.

FOUCAULT, Michel. História da sexualidade 1: a vontade de saber. 13.ed. Rio de Janeiro: Graal, 1988.

FRASER, Nancy et al. "Falsas antíteses: uma resposta a Seyla Benhabib e Judith Butler”. In: BENHABIB, S.; BUTLER, J.; CORNELL, D.; FRASER, N. Debates feministas: um intercâmbio filosófico. Trad. Fernanda Veríssimo. São Paulo: Unesp, 2018c. 
FRASER, Nancy; NICHOLSON, Linda. "Social Criticism without Philosophy: an encounter between Feminism and Postmodernism”. Theory, Culture \& Society, v. 5, n. 2-3, pp. 373-394, 1988.

HEGEL, G.W.F. Filosofia da História. Brasília: Ed. UnB, 1999.

KANT, I. Antropologia de um ponto de vista pragmático. São Paulo: Iluminuras, 2006.

LLOYD, Moya. Judith Butler: from norms to politics. Cambridge: Polity Press, 2007.

LOBATO, Ana; RODRIGUES, Carla. "Os feminismos e seus sujeitos". Revista de Filosofia, Natal, v. 27, n. 52, pp. 43- 65, 2020.

LYOTARD, J.-F. A condição pós-moderna. Trad. Ricardo Corrêa Barbosa. 6.ed. Rio de Janeiro: José Olympio, 2000.

RAWLS, John. A Theory of Justice. 2.ed. Cambridge, MA: Harvard University Press, 1971.

RUBIN, Gayle. O tráfico de mulheres: Notas sobre a economia política do sexo. Recife: SOS Corpo, 1993.

SALIH, Sara. Judith Butler e a teoria Queer. Belo Horizonte: Autêntica, 2017. 